\title{
O GIZ DA ESCOLA DA PERFORMANCE
}

\section{The performance school's chalk}

\author{
Naira Ciotti \\ Vicente Martos Moreira \\ Universidade Federal do Rio Grande do Norte
}

Resumo: Este artigo procura discutir algumas práticas de professorperformer com base na ideia de abandono social, na formação de corpos políticos em uma conexão afetiva. A relação entre política e artes é problematizada. São táticas analíticas para identificar processos de resistência contra apagamento na produção de performances em um contexto de ensino.

Palavras-chave: Performance; Professor-performer; Sobrevivência nas artes cênicas.

Abstract: This article intents to discuss some practices of professor-performer (CIOTTI, 2014), based on the idea of social abandonment, the formation of political bodies and an affective connection (SAFATLE, 2016). The relation between politics and arts is problematized. It is analytical tactics to identify, resistance process against erasure in the production of performances in a teaching context. (SASSEN, 2016).

Keywords: Performance; Professor-Performer; Surviving in Performing Arts. 
O samba não se aprende no colégio Sambar é chorar de alegria

É sorrir de nostalgia

Dentro da melodia

(Noel Rosa) $^{1}$

O lugar de fala deste artigo é o LabPERFORMANCE Laboratório de Performance e Teatro Performativo vinculado ao Departamento de Arte da Universidade Federal do Rio Grande do Norte; isto significa que ele ecoa e também evoca diferentes vozes. Uma parte foi baseada na conferência "Sobrevivência nas Artes Cênicas", apresentada por Naira Ciotti na VIII Jornada de Pesquisa em Artes Cênicas - Edição Internacional, e cuja temática/provocação foi: Sobrevivências em Artes Cênicas Articulação de conhecimentos e práticas [im]possíveis, realizada em 2 de Novembro de 2017, a convite do Departamento de Artes Cênicas - DAC / Universidade Federal da Paraíba, e que pretendia discutir as relações entre a prática de professor e a prática artística. Esse assunto pode ser compreendido como eixo fundamental deste texto, que busca relacionar a polaridade entre o professor e 0 artista.

Este artigo também apresenta uma série de trabalhos em performance arte, contemplando os primeiros trabalhos criados ou orientados por Naira em colaboração com diversos artistas em processo de formação, relacionando práticas performativas de ensino de Arte a teorias das ciências sociais e econômicas.

Finalmente, o artigo vai contemplar algumas práticas do professor-performer enquanto tática analítica. A partir da expansão da ordem visual/material, em direção a observar como se

\footnotetext{
1 "Feitio de Oração, Noel Rosa", Vadico, 1933.
}

dá a possibilidade de certas visualidades apagadas ao poderem ser novamente presentes e poderem contar suas histórias. Mostrar as primeiras performances realizadas em sala de aula agencia paradigmas não estabelecidos, sem centralidade, atua nas fronteiras do paradigma teatral e pedagógico pois propõe micro-revoluções. Saskia Sassen levanta tais perguntas para discutir os processos de expulsão e apagamento cultural (SASSEN, 2017). Essas perguntas podem também ser feitas para as imagens dos processos: o que eu não vejo nelas se eu invocar uma categoria muito poderosa? Sugiro que ao vê-las possamos nos perguntar sobre o que nós não estamos vendo (ainda).

O artigo finaliza de maneira a buscar uma interação com o leitor, quando levantamos um diálogo sobre a emergência dos conteúdos autobiográficos na arte e a sua importância política a partir da construção de referências de fronteiras mais ambíguas, propondo a ocupação intelectual nas fronteiras sistêmicas entre a arte e a política. $O$ que não vemos ao se construir e manifestar biografias pessoais, visões de mundo e formas de vida.

\section{Sobrevivência}

\begin{abstract}
Quando eu comecei a trabalhar com isso lá no século passado, era uma coisa meio estranha, era uma condenação para um artista virar professor de arte. Parecia que a gente não ia nunca mais trabalhar com arte; ou você era professor de arte ou trabalhava com arte. Não havia tempo, não havia espaço, não havia corpo que desse conta dessas duas atividades. (Informação verbal CIOTTI, 2017)
\end{abstract}

O primeiro trabalho que apresentamos neste estudo aconteceu ainda nos anos 1990 e 
chama-se "A Conversa Entre Lygia Clark e Hélio Oiticica", desenvolvido a partir da proposta de criar um grupo de estudos práticos de Performance na faculdade de Arquitetura. Esse grupo de estudos pretendeu colocar alunos de Arquitetura em contato com outras formas de espacialização e percepção do espaço, do corpo e dos estudos das sensações, a partir das obras dos dois artistas citados. Por ocorrer numa região conhecida pelas grandes manifestações sindicais, a formação do Partido dos Trabalhadores e de grande parte do que hoje identificamos como a esquerda política do país, pressupõe-se o viés político desse território e de seus habitantes.

A importância em abordar as obras citadas, bem como dos estudos da Performance de uma maneira geral, apontava para a necessidade de uma abordagem mais sensível em relação às políticas do corpo. "No curso de Arquitetura, [os alunos] eram pessoas que para ter aula eu tinha que convencer, por 20 minutos da aula, que se podia tirar os sapatos, que era normal, que tudo bem ficar sem sapatos" (informação verbal CIOTTI, 2017). A performance resultante das práticas foi apresentada nas dependências da Universidade em que já trabalhava, e também no Congresso da COMPÓS - Associação Nacional dos Programas de Pós-Graduação em Comunicação², fundada em 16 junho de 1991, em Belo Horizonte, com o apoio da Capes e do CNPq, a partir da iniciativa de alguns pesquisadores e representantes dos cursos de Pós-Graduação: PUC-SP, UFBA, UFRJ, UnB, UNICAMP, UMESP, onde aconteceu em um palco, ou seja, um espaço construído especificamente para

${ }^{2}$ Conf. <http://www.compos.org.br/a_compos.php>. apresentações artísticas, com iluminação e todo o aparato cênico.

Uma segunda ação desenvolvida na faculdade de Arquitetura foi a Oficina de Performance. 'Nós começamos a fazer alguns trabalhos no espaço, trabalhos de travessia, trabalhos que eu estava desenvolvendo com Renato Cohen ${ }^{3}$ na época" (informação verbal CIOTTI, 2017). Durante 0 ano das comemorações dos quinhentos anos de descoberta do Brasil, a oficina desenvolveu um trabalho ligado à identidade da região do $\mathrm{ABC}$, que, apesar de ter essa característica de politização, convive diariamente com a ausência do que poderíamos chamar de um "mito de origem".

Segundo essa inquietação, o grupo se deparou com a história de João Ramalho, um dos primeiros bandeirantes que chegaram no Brasil. Segundo consta na literatura, o aventureiro sofreu um naufrágio em São Vicente e lá foi resgatado e abrigado pelo império Tupiniquim. Por ser bem acolhido, aprendeu a língua dos nativos e casou-se com a princesa desse império, a índia Bartira. Logo depois, construiu a primeira vila no Brasil, que seria Santo André da Borda do Campo, uma região que hoje em dia pode ser acessada a partir do caminho que leva os paulistas à cidade de São Vicente. É uma das primeiras regiões habitáveis, há abundância de água e os terrenos se tornam mais planos, facilitando a sobrevivência. A cidade, fundada por João Ramalho, recebeu de Portugal o Pelourinho, construindo também a Casa de Câmara e Cadeia, organizando e viabilizando todo o aparato legislativo do local.

\footnotetext{
3 Renato Cohen (1956 - 2003), foi um ator, diretor, performer, teórico e pesquisador brasileiro, autor dos livros "Performance como Linguagem" (1989) e "Work in progress na cena contemporânea" (2002).
} 
Na segunda expedição da coroa portuguesa ao Brasil, foram enviados os padres jesuítas para catequização dos povos nativos. Ao chegarem, esses mesmos padres encontraram, nas novas terras, portugueses e tupis convivendo em harmonia. Isso não foi muito bem aceito e então, após resolução da Coroa, a fundação da cidade orignal tornou-se uma espécie de proibição, pois o Pelourinho foi enviado para a vila de Santa Cruz, onde permanece até os dias de hoje em exposição ${ }^{4}$.

A história da fundação da cidade e a formação social que se experimentou por aquele curto período foi abandonada, apagada. 'Em performance nós temos condições de reperformar os arquivos, de ir atrás das coisas e incorporar isso, enactuar, trazer para o corpo, e foi o que nós fizemos" (informação verbal CIOTTI, 2017). Os participantes da oficina reconstruíram o mito, com o intuito de aproximar a região com esse sitio fundador. $O$ primeiro passo foi estabelecer o território, a geografia imaginária dessa cidade ancestral. Trabalhamos com a ideia de que essa cidade de João Ramalho teria permanecido submersa na represa Billings, que é um dos mais importante corpos de água da região metropolitana da cidade de São Paulo, representando um papel estratégico no abastecimento de água numa área de pressão pela urbanização do seu entorno.

Não havia público, era uma ação onde todos participavam como performers para recomeçar o Brasil 500 anos depois. A imagem a seguir é extraída do resultado desta ação, e foi posteriormente inserida em um outdoor,

\footnotetext{
4 Solar da Marquesa fica localizado na rua Roberto Simonsen, 136 Centro - São Paulo/SP (próximo ao metrô Sé) e oferece visitação monitorada e gratuita de terça-feira a domingo, das 9 às 17h. In: uww.museudacidade.sp.gov.br/solardamarquesadesantos.php
}

seguida da frase "Brasil 500 anos. João Ramalho, o europeu à deriva".

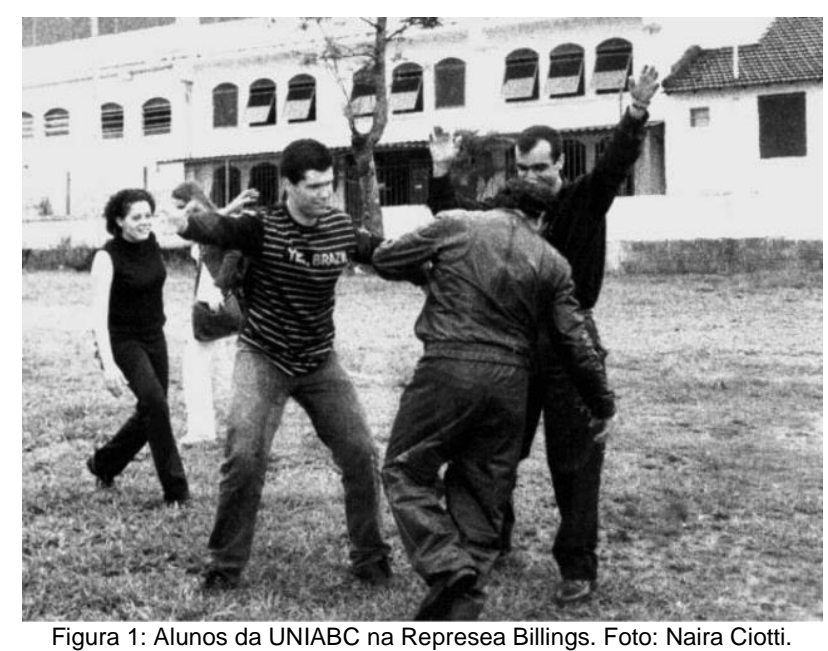

\section{Práticas performativas em Artes Cênicas}

Em 1999 foi criado na PUC/SP o curso de Comunicação das Artes do Corpo, Naira Ciotti, juntamente com a coordenação, ou seja, Christine Greiner, e os professoresartistas Renato Cohen, Lúcio Agra, Samira BR e João André da Rocha projetaram alguns anos depois um curso de performance composto por práticas e discussões teórico-estéticas. Na hibridação com as linguagens do corpo foram elaborados laboratórios de criação de performances relacionais em Work In Progress.

Ao longo dos últimos dez anos, no curso de Licenciatura em Teatro da Universidade Federal do Rio Grande do Norte, seguimos disseminando o pensamento acerca da arte da performance, tentando e errando, para incluir nos conteúdos específicos da arte teatral, as táticas performativas. Com o passar dos anos, agora com maior participação dos discentes, estamos experimentando novos espaços de compartilhamento pedagógico para dar 
conta da complexidade teórica dos estudos da Performance, porém sem abrir mão de insistir nos processos e conteúdos emergentes.

É notável que o estado atual do ensino da performance, ou ao menos da preocupação das escolas de arte do Brasil com esse assunto, só tem aumentado. Cada dia é possível perceber mais pessoas, profissionais, artistas ou alunos interessados em performance. A performance, por sua vez, assim como as outras linguagens artísticas contemporâneas, evoluiu ao longo desse tempo, o que significa que essa linguagem não estagnou-se em conceitos originais que guiaram artistas como Joseph Beuys, Hélio Oiticica e Lygia Clark.

Performance é um termo amplo, também se transformou ao longo deste nosso novo século. Após a revolução das redes de comunicação a palavra, que remetia a uma linguagem das Artes do Corpo, passou a significar experiências de hibridação de meios com ênfases em explorações conceituais.

No limiar do século XXI, a performance foi atravessada pela tecnologia. Daí pra frente todo o nosso cotidiano contém traços de performance. Nas conexões com as máquinas, na produção de imagens. $O$ teatro, a literatura e a dança consumiramse nas virtualidades e possibilidades de interação, intervenção e compartilhamento de afecções subjetivas.

\section{Sobre Performance, Arte e Política}

A obra é, queira eu conscientemente ou não, " para o outro". Portanto, a aparente e tão discutida oposição entre "arte pura" e "arte engajada" não passa de mal entendido. Toda arte, se for arte, é pura no ato. E toda arte, se for arte, é engajada no efeito do ato. A política é o resultado não pretendido, mas necessário, da arte. (FLUSSER, 1972, p. 87)

$\mathrm{Na}$ atualidade, quando falamos de performance estamos falando em intervenção urbana, "em dançar na cidade", em manifestações políticas, em ações pedagógicas, em direção a paradigmas sociais e estéticos. Um dos entendimentos do conceito de paradigma é de que trata-se de uma constelação de crenças, valores, técnicas etc., partilhada pelos membros de uma comunidade determinada. $\mathrm{O}$ paradigma é um lugar onde esta ideia pode ser compartilhada por uma comunidade científica. Segundo o seu criador, Thomas Kuhn (2011, p. 249), não é um objeto de estudo, mas uma constelação de pessoas praticantes de uma ciência, uma inscrição disciplinar. Nesse sentido, vive-se uma mudança de paradigma em relação a arte da performance e, consequentemente, do seu estudo e pesquisa. Os artistas que trabalham com conteúdos autobiográficos, na atualidade, relacionam-se ao mesmo tempo com motivações políticas, respostas à circuitações afetivas provenientes de diversas fontes.

Havia antes uma relação entre arte e política, sempre houve, mas ela não era profundamente discutida nem profundamente investigada, principalmente por quem trabalhava com relatos autobiográficos, com histórias de vida, com questões pessoais. Sempre foi uma questão meio paralela: todo mundo tinha as suas posições políticas mas não necessariamente isso entrava na 
ação, na sala de ensaio ou no espetáculo que a gente estava montando. (Informação verbal CIOTTI, 2017)

Depois de 2016 - num processo que na verdade pode ter se iniciado como uma tendência que veio de 2013, mas que mais recentemente se configurou de forma mais clara, tornou-se impossível, do nosso ponto de vista, separar arte e política. Não existe mais possibilidades em se falar de arte no Brasil, e em muitos lugares do mundo, sem falar de política. $O$ artista, à medida em que investiga a própria biografia em relação com a coletividade, a universalidade, enraiza-se cada vez mais nas suas circunstâncias sociais e políticas.

Este estudo compreende e propõe a importância da uma melhor elaboração científica e artística acerca do tema "sobrevivência" nas Artes Cênicas porque sobreviver tem se tornado uma questão bastante recorrente na produção dos artistas da performance.

Assim como a Arte, a Educação pública vem sofrendo recorrentes ataques orçamentários, congelamentos de investimentos e privatizações. Tivemos, em 2016, as manifestações estudantis dos alunos secundaristas com a ocupação de mais de cem escolas de ensino fundamental e médio, seguida sempre de forte repressão pelos Estados. No segundo semestre do mesmo ano, após o anúncio da Proposta de Emenda Constitucional PEC 241, estudantes e docentes das Universidades Federais em todo território nacional ocuparam as reitorias e outros espaços das instituições. As aulas, transferidas para esses locais, tiveram suas muitas dinâmicas pedagógicas alteradas nesse momento, fazendo eclodir encontros e práticas de compartilhamento entre docentes e discentes, instaurando novas ordens no campo do ensino e também do ensino de arte $^{5}$.

Em Natal, de tempos em tempos, reunimos no Laboratório de Pesquisa em Performance e Teatro Performativo os pesquisadores de pós-graduação e alunos da graduação interessados em discutir alguns temas ou inquietações que temos percebido serem importantes campos de reflexão para o trabalho artístico. Dentro dessa busca encontramos a ideia de "expulsão", apresentada por Saskia Sassen em seus estudos ${ }^{6}$. Nosso desejo aqui não é fazer uma explanação complexa dos conceitos levantados por essa autora, mas traçar um paralelo entre seus apontamentos e possíveis práticas que temos investigado no campo da performance em interface com a educação. O que é pensar na expulsão? O que é pensar em uma desigualdade social que não pára de crescer e que acaba por expulsar as pessoas dos seus lugares, seja ele o país, o emprego, a sala de aula, a cidade propriamente dita, as suas casas.

Se a desigualdade (global) continuar crescendo, em algum momento poderá ser descrita, mais precisamente, como uma forma de expulsão. Para aqueles que estão na

\footnotetext{
${ }^{5} \mathrm{Em}$ 2016, em paralelo à ocupação da reitoria da UFRN pelos coletivos de resistência estudantis contra a PEC 241, alunos de Licenciatura em Teatro, pesquisadores do Laboratório de Pesquisa em Performance e Teatro Performativo e artistas convidados realizaram a primeira edição do evento Reperformar o Afeto, maiores informações e demais conteúdos relacionados podem ser obitidos no endereço: $<$ http://vicentemartos.wixsite.com/reperformaroafeto >.

${ }^{6}$ Ver "Expulsões", de Sassia Sasken, 2017
} 
parte mais baixa da escala, ou em sua metade pobre, isso significa a expulsão de um espaço de vida. Para os que estão no topo, parece ter significado 0 fim das responsabilidades como membros da sociedade por meio da auto superação, a extrema concentração de riqueza disponível numa sociedade e a falta de inclinação a distribuir essa riqueza. (SASSEN, 2016, p. 24)

No Laboratório de Performance, em consonância com essas ideias, podemos recortar alguns dos experimentos.

A Imagem abaixo mostra uma aula da disciplina de Estudos da Performance, oferecida na graduação em Teatro no segundo semestre de 2017. Na imagem a aluna Badu Morais experimenta performar com todo o seu aparato de mãe recente mamadeiras, fraldas, brinquedinhos, remédios etc., que deixam de ser apenas utilitários para se tornarem um peso a ser suportado; a performer, nos propõe pensarmos nos corpos, práticas e processos que seguem desamparados pelo sistema capitalista neo-liberal.

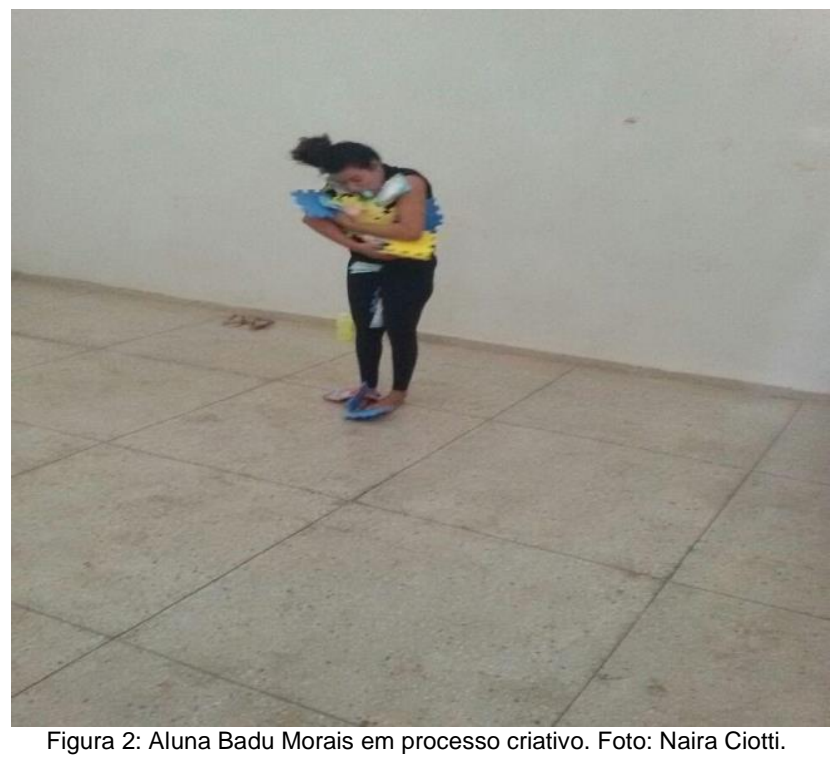

Para falarmos de expulsão, apagamento e desamparo é preciso entender alguns dados da economia mundial. A questão geral, segundo Sassen, aquela que causa e sustenta as crises financeiras ao redor do mundo, é que todos os estados já estão endividados. Essas dívidas foram contraídas não porque as pessoas estouraram o limite dos seus cartões de crédito e não conseguiram pagar, tornandose inadimplentes. A dívida existe por razões como o alto número de isenções fiscais e subsídios para que as empresas se instalem em uma cidade ou outra. As dívidas dos bancos tornaram-se impraticáveis, chegando a níveis jamais vistos antes e, paradoxalmente, perdoadas pelos estados, ou porque Donald Trump não pagou a UNESCO o que os EUA deviam no ano anterior, para citar alguns exemplos. ${ }^{7}$

A medida em que várias empresas pura e simplesmente se recusam a pagar as suas dívidas, isso vai tornando os estados endividados. O que nos afeta diretamente porque 0 que os estados fazem para regular suas economias é reduzir os direitos civis.

O que afirmo aqui é que caímos sob a influência de um conceito perigoso e limitado de crescimento econômico. $O$ crescimento, claro, era essencial para o projeto do Estado de bem-estar

\footnotetext{
${ }^{7}$ Em outubro de 2017 o presidente dos estados Unidos Donald Trump anunciou que seu país se retirará da UNESCO por discordar das posições políticas da entidade em relação à questão palestina em Israel, mas o Jornal do Brasil informa que "muitos periódicos como o Foreign Policy, por exemplo, especulam que também tenha pesado para a decisão a dívida de US\$ 500 milhões dos EUA com a Unesco. Disponível em: $<\mathrm{http}: / / \mathrm{www} . j \mathrm{~b} . c 0 m$. br/internacional/noticias/2017/10/12/governotrump-retira-estados-unidos-da-unesco/>. Acesso em 30/04/2018.
} 
social. Mas também era um meio de promover o interesse público, de fazer aumentar uma prosperidade que seria compartilhada por muitos, embora muito mais por alguns do que por outros. Em comparação, hoje nossas instituições e nossos pressupostos estão cada vez mais a serviço do crescimento econômico corporativo. Essa é a nova lógica sistêmica. Talvez não todas, mas um número suficiente de empresas procurou se libertar de quaisquer restrições, incluindo as de interesse público local, que interfiram na sua busca de lucro. Qualquer coisa ou qualquer pessoa, seja uma lei ou um esforço cívico, que dificulte a obtenção de lucro corre o risco de ser posta de lado, de ser expulsa (SASSEN, 2016, p. 253)

O que interessa para a performance num estudo minucioso sobre dados financeiros e situações econômicas em torno do globo terrestre é que essas expulsões, quando se trata de gente, se transformam em apagamentos de arquivos, apagamentos de histórias de vida, apagamentos de propostas vanguardistas de educação, apagamentos de experiências de intervenção e, novamente, de dançar na cidade. As populações e os seus deslocamentos, geográficos ou culturais, vão se apagando para se transformar em estatística. É sério? É. Os performers têm que pensar nisso? Têm.

Surge assim um norte visual com seus modos de vida, e aqueles que não correspondem à esse norte visual tornamse os excluídos, os refugiados, os imigrantes, os que ocuparam os prédios abandonados, os que estão reivindicando seus direitos perdidos sem nenhuma esperança.
Essas expulsões ocorrem numa lógica de apagamento que acontece na ordem do visual e também do material; elites econômicas tornam-se o norte visual - assim como seus modos de vida. $\mathrm{E}$ as populações que não correspondem às dinâmicas econômicas das cidades contemporâneas passam a ocupar um estado de invisibilidade e, consequentemente, de expulsão (...) São indivíduos que constam em números estatísticos - a quantidade de desempregados no Brasil no último ano, a quantidade de pessoas desabrigadas pela guerra no Oriente Médio, a quantidade de refugiados que a Alemanha recebeu em seu território nos últimos anos. Esses indivíduos não fazem parte do norte ideológico, aquele que compõe a lista dos desejos permeantes, das prioridades em nossas sociedades. (Informação verbal CIOTTI, 2017)

Um exemplo apresentado por Saskia Sassen para ilustrar o absurdo de certos sistemas neoliberais de expulsão é o fato de que, até 2017 , existem ao todo noventa e três pessoas no mundo sem nenhuma identidade de estado e que não poderão voltar a tê-la. Essas pessoas perderam o país!

Em uma outra imagem que trazemos de nossos estudos, da mesma disciplina de Estudos da Performance, o aluno Bruno Silva está fazendo um trabalho que de alguma forma dialoga com essa ideia do apagamento, de mostrar-se, de querer deixar de ser uma identidade não representada. 


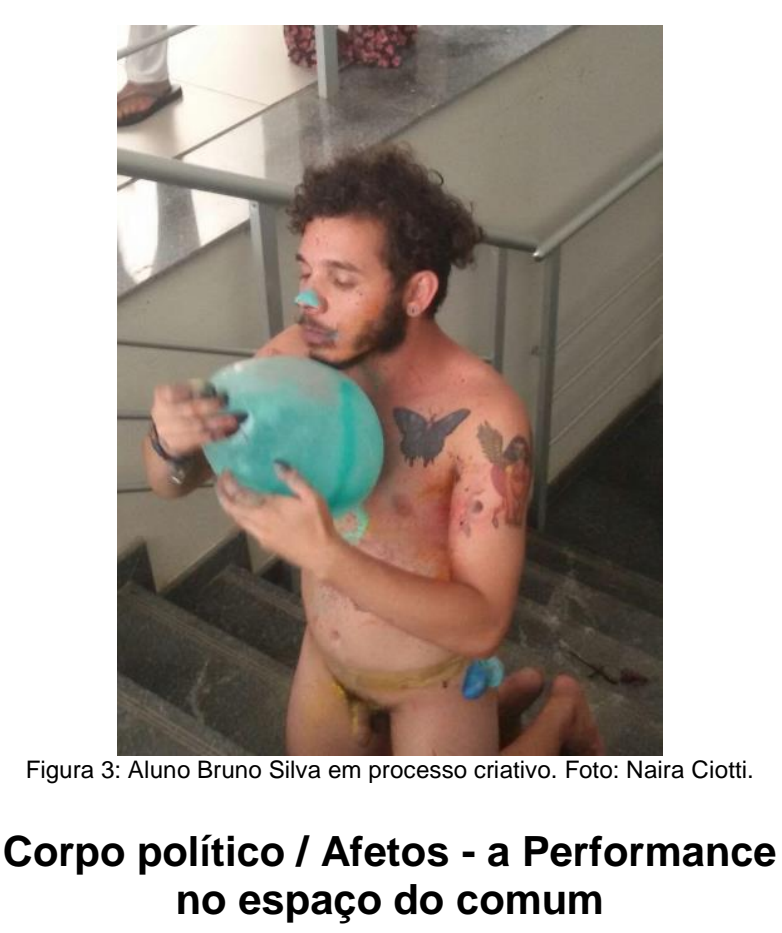

Para nos ajudar nessa construção trazemos também o autor Antonio Negri, com a ideia de uma realidade pósglobalização. Negri aponta para a possibilidade de descobrirmos uma:

alternativa para o corpo político global no
reconhecimento da cooperação e
comunicação, na produção de
subjetividade que poderia engendrar um
outro corpo, o corpo comum. [...] A carne
produtiva comum da multidão adquiriu a
forma de corpo político global do capital,
dividido geograficamente por hierarquias
de trabalho e riqueza e governado por
uma estrutura multinivelada de poderes
econômicos, jurídicos e políticos. (NEGRI
e HARDT, 2005, p. 247)

Em 2017, notamos que existe o espaço público, o espaço privado e a performance. Essa prática contemporâneas vai abrindo zonas fronteiriças que estimulam a construção desse corpo comum. Não é um corpo da comunidade, é um corpo que não está nem no privado e nem no público. Algo como um espaço efêmero que se cria e se desfaz na medida em que a performance se faz presente num determinado local com determinados indivíduos e suas histórias.

Outro autor que ajuda a provocar estas discussões é Vladimir Safatle, que traz o conceito de circuito dos afetos (SAFATLE, 2016). Segundo esse estudo, as sociedades, os sistemas econômicos e políticos produzem, em seu nível fundamental, circuitos de afetos, que as constituem. Isso vem sendo problematizado em várias instâncias acadêmicas que estão discutindo arte contemporânea. Durante muito tempo deixamos não só a política de lado, mas toda a pulsão dos afetos, dos desejos, do amor. Numa sociedade precisamos uns dos outros, no entanto, o que fazer dessas relações, que são de altíssima complexidade e que foram pura e simplesmente abandonadas?

Sabemos que as pessoas funcionam por afeto. Por exemplo, quem está à frente de um elenco cujos atores não tem nenhuma ligação com o espetáculo, sabe que não vai conseguir montar este espetáculo. De outro lado, se um elenco está empolgado pelo que está fazendo, as vezes, não se tem um espetáculo, mas existe um trabalho. É a mesma coisa com a nossa sociedade, nós nos deixamos afetar o tempo todo.

Acordamos todas as manhãs e abrimos nossos dispositivos para acessar redes sociais. Nem bem acordamos e já sabemos de tudo, e já estamos todos afetados - "se o Caetano não pode cantar eu já estou assim, se - Caetano pode cantar eu já estou de outro jeito"8. Por consequência, nas instâncias do

\footnotetext{
${ }^{8}$ Segundo o site G1"O cantor Caetano Veloso lamentou a decisão da Justiça que impediu que ele fizesse um show
} 
poder, funciona da mesma maneira. Dentro do conjunto de configurações: "Em sua coletividade, os afetos configuram corpos políticos, ou seja, massas de corpos que representam determinados discursos e se movem através deles, podendo por eles ser expressos com uma noção arbitrária de individualidade" (CIOTTI e MOREIRA, 2017, p. 17).

Então a nossa afetividade com relação a um tema, não é simplesmente escolhida por nós; fazemos escolhas porque estamos circuitados com essas questões, e esta circuitação é interessante para os performers no século XXI.

\section{Perguntas para uma proposta política de Autobiografia}

Outra imagem também do nosso Laboratório trata-se do grupo da disciplina de Encenação 4, que trabalhou em 2017 com um texto do dramaturgo alemão Peter Handke, datado dos anos 1960 e chamado "Autoacusação" (HANDKE, 2015). Podemos perceber como funcionam essas circuitações numa situação de laboratório teatral, durante um dos ensaios, no mês de setembro, tendo em vista a inclusão de dramaturgias criadas a partir de procedimentos biográficos/reais dos performers envolvidos.

na ocupação do Movimento dos Trabalhadores Sem Teto (MTST) em São Bernardo do Campo, no ABC paulista. "Ser impedido de cantar não é bom. Mais do que nunca é preciso cantar, como diz a música de Vincius de Moraes (Marcha de Quarta-feira de Cinzas). Porque há muita dificuldade", disse Caetano, que foi ao terreno ocupado por seis mil famílias.". Disponível em: $<$ https://g1.globo.com/sao-paulo/noticia/caetano-e-aprimeira-vez-que-sou-impedido-de-cantar-no-periododemocratico-diz-em-ocupacao-do-mtst.ghtml>. Acessado em 30/04/2018.

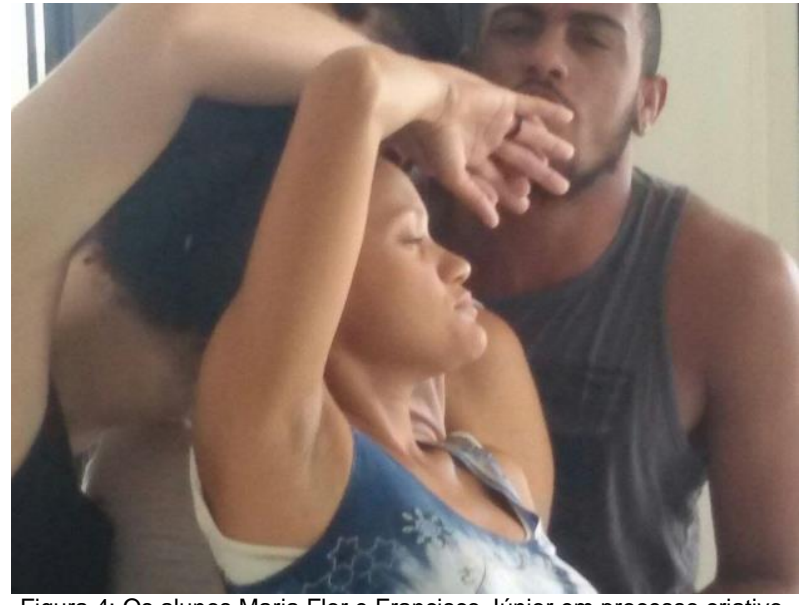

Figura 4: Os alunos Maria Flor e Francisco Júnior em processo criativo. Foto: Naira Ciotti.

Da mesma forma como foi mostrado na primeira imagem deste texto, vemos nesse trabalho, que relacionava biografias pessoais de alunos do Rio Grande do Norte com o texto do autor austríaco uma representação dessa ilusão de que somos um indivíduo, ou seja, mais uma situação geral de desamparo. Quais circuitações ela nos provocam?

Pensar na teoria do desamparo proposta por Safatle indica que somos coletivos, nos conectamos, nos aproximamos, nos afastamos ou repelimos o tempo todo. O tempo todo, nós estamos em relação uns com os outros. E esse é um material muito interessante para a arte da performance.

\section{Conclusão}

O que o performer, que está interessado em arte, que trabalha com auto-biografia, com estados corporais, com vários princípios com o os quais somos totalmente favoráveis, como colocado anteriormente neste artigo, pode pensar? Que perguntas poderíamos fazer para esses performers ativistas? Diante desse jogo político, dessa estrutura toda, dessa circuitação dos afetos 
políticos, quem eu sou? Ou ainda: eu tenho certeza de quem eu sou?

As outras perguntas seriam: o que existe na política além de acusações? É possível trabalharmos com as derrotas $e$ as performances, as manifestações contra a Dilma, contra o PT, contra o Temer, desconstruindo arte-política do teatro, das mídias e dos seus dispositivos?

O performer hoje pode contar sua biografia ultrapassando a sua vida pessoal? Ou como perguntou Rabih Mroué ${ }^{9}$ : onde você estava quando estava acontecendo 0 impeachment de Dilma Roussef? Ele fez essa pergunta para um grupo de mais ou menos vinte performers que participavam de um workshop que ministrou na Mostra Internacional de Teatro de São Paulo ${ }^{10}$. As respostas dos performers foram, em geral que: um tinha ido para casa da tia, o outro tinha ido para o metrô e ficou preso lá, outro acompanhou manifestações pela internet ou até ao vivo, presencialmente nas ruas. O diretor apontava para o fato de que essas histórias nunca são contadas, esses pontos de vista seguem apagados.

\footnotetext{
${ }^{9}$ Rabih Mroué é um dos proeminentes nomes das artes visuais e da performance no Líbano, participou das últimas edições da Documenta, entre outros é fundador do Beirut Art Center. A narrativa de Mroué aproxima fatos reais e fantasiados com a mesma credibilidade. $\mathrm{O}$ trabalho dele se liga à trágica história do período de conflitos políticos no Libano sem recorrer à reivindicação sentimental das vítimas ou a representação visceral da violência, segundo Inti Guerrero, Rabih Mroué tem habilidade para conectar histórias pessoais à história. Informações coletadas no site http://site.videobrasil.org.br/news/1784545

10 Participei do Workshop BRASIL EM PIXELS, com Rabih Mroué inspirado no processo de criação de seus últimos espetáculos. Além de partilhar elementos de sua pesquisa cênica, Rabih propôs aos participantes um trabalho criativo baseado em fotos das manifestações brasileiras de 2016, a fim de estimular a reflexão: que narrativa emerge dessas imagens? Mais informações disponíveis em <http://mitsp.org/2017/acoespedagogicas/\#_workshop >.
}

O samba, a Arte, não se aprendem no colégio, é uma atividade emocional, que o colégio não pode acessar. Nossa ideia de performance vem da senzala da escravidão brasileira, vem dos terreiros, partiu do samba e seus afetos. A performance também veio dos estudos sobre as atividades humanas mais amplas $\mathrm{e}$ espontâneas. No teatro e suas teorias contemporâneas a performance expõe a condição reflexiva de sujeitos fragmentados e os corpos por eles engendrados: mutantes, transformers, performeros, artivistas, tatuadores, produções de semiose e asemiose (GUATTARI, 2011). A performance escancara as subjetividades através das estéticas do sul, latinidades, a descida antropofágica de Viveiros de Castro. Neste momento o século $X X$ e XXI entram em conexão, a performance entra no colégio pelas portas da Universidade. "Houve sim, uma virada educativa no Brasil, que está em curso, nos somos resultado disso, a Unicamp, a UFRN a PUC todos temos a ver com este investimento em abrir o campo das Artes para os não especialistas e para a formação de platéias e novos artistas" (informação verbal CIOTTI, 2017).

De uma forma bem brasileira, agora que formamos diversos novos professores, a política de educação parece mudar drasticamente. Estamos atravessando o contraponto disso, que pode encaminhar estas iniciativas para o abismo. Como uma tática para a sobrevivência nas Artes Cênicas e no Ensino de Arte, precisamos nos indagar: como construir uma ponte de professores híbridos?

Recebido em:18/04/2018

Aceito em:15/05/2018 


\section{Referências Bibliográficas}

CIOTTI, Naira. O professor-performer. Natal: EDUFRN, 2014.

CIOTTI, Naira e MOREIRA, Vicente Martos. Residência artística: corpos-políticos e táticas analíticas aos processos de apagamento. In: PIXO: Revista de arquitetura, cidade e contemporaneidade. V.1 N.2 2017. Disponível em: $<$ http//dx.doi.org/10.15210/pixo.v1i2.11616>. Acessado em 20/02/2018.

FLUSSER, Vilém. Arte de retaguarda. Cavalo Azul, (7): 79-89, 1972. Disponível em: $<$ http://www.dubitoergosum.xpg.com.br/a597.ht $\mathrm{m}>$. Acessado em 20/02/2018.

GATTARI, Felix. Máquina Kafka. São Paulo: n1 Ed., 2011.

GUERRERO, INTI. Artista libanês relaciona memórias entrecortadas e elementos oníricos. Disponível em: <http://site.videobrasil.org.br/news/1784545>. Acessado em: 24/02/2018.

HANDKE, Peter. Peças Faladas. São Paulo, ed. Perspectiva, 2015.

KUHN, Thomas. A estrutura das revoluções científicas. São Paulo: Perspectiva, 2011.

NEGRI, Antonio e HARDT, Michel. Multidão: guerra e democracia na Era do Império. Rio de Janeiro: Ed. Record, 2005.

SAFATLE, Vladimir. 0 circuito dos afetos: Corpos políticos, desamparo e o fim do indivíduo; Belo Horizonte: Autêntica, 2016.

SASSEN, Saskia. Expulsões: Brutalidade e complexidade na economia global. Rio de Janeiro/São Paulo: Paz \& Terra, 2016.

"Governo Trump retira Estados Unidos da Unesco." Jornal do Brasil, 12/10/2017. Disponível em: <http://www.jb.com.br/internacional/noticias/2 017/10/12/governo-trump-retira-estadosunidos-da-unesco/>. Acessado em 24/02/2018.

\section{Referências Orais:}

CIOTTI, Naira. "Sobrevivência nas Artes Cênicas". Conferência apresentada durante a VIII Jornada de Pesquisa em Artes Cênicas - Edição Internacional: Sobrevivências em Artes Cênicas Articulação de conhecimentos e práticas [im]possíveis. João Pessoa: Departamento de Artes Cênicas, Universidade Federal da Paraíba, em 02/11/2017. 